\title{
PENGARUH PARTISIPASI PELANGGAN TERHADAP KINERJA PELAYANAN PUBLIK DI BRI UNIT OTTING KECAMATAN DUAPITUE KABUPATEN SIDENRENG RAPPANG
}

\author{
Hasnada \\ Ilmu Pemerintahan, FISIP, Universitas Muhammadiyah Sidenreng Rappang, Sidrap, Sulawesi Selatan, Indonesia
}

Email hasnada955@gmail.com

\begin{abstract}
Abstrak
partisipasi masyarakat merupakan keterlibatan atau keikutsertaan seseorang masyarakat dalam proses interaksi sosial, pengidentifikasian masalah dan potensi yang ada di masyarakat dalam situasi tertentu, baik dalam pengambilan keputusan (solusi) menangani masalah, pelaksanaan upaya mengatasi masalah, dan proses keterlibatan masyarakat di dalam mengevaluasi perubahan yang terjadi.(Mustanir \& Abadi, 2017). pelayanan prima bukan hanya tugas badan

usaha milik negara atau instansi swasta bahkan lembaga yang diisi para pegawai negeri sipil pun harus memberikan pelayanan prima. Lambatnya pemberian pelayanan semakin merusak citra pegawai negeri sipil sebagai sumber daya manusia yang lemah kompetensi dan malas. Citra itu akan semakin melemah ketika di era pandemi ini banyak pembatasan yang dilakukan terkait pelayanan. Bahkan seharusnya, ketika di masa pandemi inilah momentum yang baik untuk melakukan perubahan ke arah yang baik.(Kurdi, 2020)
\end{abstract}

kata kunci ; Partisipasi dan Pelayanan publik

\begin{abstract}
Abstrak
Community participation is the involvement or participation of a person in the community in the process of social interaction, identifying problems and potentials that exist in the community in certain situations, both in making decisions (solutions) dealing with problems, implementing efforts to overcome problems, and the process of community involvement in evaluating changes that occur. .(Mustanir \& Abadi, 2017). excellent service is not just a body job State-owned enterprises or private institutions and even institutions filled with civil servants must provide excellent service. The slow delivery of services is increasingly damaging the image of civil servants as human resources who are weak and lazy. That image will weaken even more when in this pandemic era many restrictions are placed on services. In fact, during this pandemic, this is a good momentum to make changes in a good direction. (Kurdi, 2020)

keywords ; Public participation and service
\end{abstract}




\section{PENDAHULUAN}

Partisipasi diberi makna sebagai keterlibatan masyarakat dalam proses politik yang seluas-luasnya baik dalam proses pengambilan keputusan dan monitoring kebijakan yang dapat mempengaruhi kehidupan mereka. Berbagai peraturan yang memberikan ruang bagi partisipasi masyarakat secara substantif belum mengatur bagaimana partisipasi masyarakat itu dilaksanakan. (Mustanir \& Abadi, 2017)

Partisipasi masyarakat tidak hanya dipandang sebagai bagian dari proses tetapi juga merupakan bagian tujuan, dimana partisipasi merupakan salah satu indikator yang mempengaruhi hasil pembangunan Sumber Daya Manusia.(Andi Uceng, 2019)

Pengertian partisipasi sendiri sangat beragam. Dalam konteks ini, partisipasi di artikan sebagai keterlibatan masyarakat secara aktif dalam setiap tahapan pembangunan mulai dari perencanaan hingga pelaksanaan. Masyarakat tidak lagi menjadi objek dari pembangunan tetapi menjadi subjek pembangunan, dimana masyarakat berperan dalam menyampaikan aspirasi, menentukan pilihan, memanfaatkan peluang dan menyelesaikan masalahnya.(Mustanir et al., 2018)

Partisipasi memiliki maksud dasar menjadi instrumen yang memberikan peluang yang besar bagi masyarakat untuk dapat berkembang sesuai dengan potensinya, terlibat aktif dalam penyelenggaraan pemerintahan,sehingga pihaknya dapat menikmati manfaat dari kebijakan, yang dibuat pihak pemerintah. Namun jika kita melihat ke belakang, bahwa mulai dari tahap perencanaan pembangunan yang menggunakan pola berjenjang dari bawah ke atas (Bottom-Up) ternyata tidak banyak menjanjikan aspirasi murni warga desa untuk didengar. (Latif et al., 2019)

Pengertian Partisipasi Masyarakat Indikator Partisipasi Masyarakat menurut Mubyartoadalah:

a) Terlibat memikul tanggung jawab pelaksanaan pembangunan

b) Musyawarah perencanaan pembangunan

c) Pelaksana hasil perencanaan pembangunan

d) Kesediaan membayar iuran sebagai dana swadaya

e) Kesediaan masyarakat dalam menyumbang material seperti pasir, batu bata, semen. (Mustanir \& Darmiah, 2016)

Rakyat berharap pada pemerintah agar dapat terselenggaranya good governance, yaitu penyelenggaraan pemerintahan yang efektif, efisien, transparan, akuntabel, dan bertanggung jawab. Efektif artinya penyelenggaraan tepat sasaran sesuai dengan perencanaan strategis yang ditetapkan, efisien artinya penyelenggaraan dilakukan secara hemat berdaya guna dan berhasil guna, transparan artinya segala kebijakan yang dilakukan oleh penyelenggara negara itu adalah terbuka, semua orang melakukan dapat pengawasan secara langsung sehingga 
mereka dapat memberikan penilaian kinerjanya terhadap hasil yang dicapai, akuntabel artinya penyelenggara pemerintah bertanggung jawab terhadap kebijakan yang ditetapkan, serta mempertanggungjawabkan kinerjanya kepada seluruh warga negara pada setiap akhir tahun penyelenggaraan pemerintahan.(Latif et al., 2019)

Mengapa pelayanan prima sangat dinantikan oleh pelanggan. Suminar et al (2017:6-7) merinci rambu-rambunya sebagai berikut:

1. Pelayanan yang terbaik dari pemerintah kepada pelanggan atau pengguna jasa.

2. Pelayanan prima ada bila ada standar pelayanan.

3. Pelayanan prima bila melebihi standar atau sama dengan standar. Sedangkan yang belum ada standar pelayanan yang terbaik dapat diberikan pelayanan yang mendekati apa yang dianggap pelayanan standar dan pelayanan yang dilakukan secara maksimal.

4. Pelanggan adalah masyarakat dalam arti luas; masyarakat eksternal dan internal.(Kurdi, 2020)

Inovasi distribusi dengan memanfaatkan perkembangan teknologi informasi (IT) perlu dilakukan dan di implementasikan agar pelayanan dapat semaksimal mungkin.

(Fitrah et al., 2021)

Berdasarkan dari fakta tersebut di atas bahwa perilaku pelanggan sangat ditentukan oleh cara pelayanan yang dilakukan pegawai bank unit otting Kecamatan duapitue Kabupaten Sidenreng Rappang.(Mustanir \& Jaya, 2016)

\section{METODE}

Pelayanan publik menjadi tolok ukur keberhasilan pelaksanaan tugas dan pengukuran kinerja pemerintah melalui birokrasi. Pelayanan publik sebagai penggerak utama juga dianggap penting oleh semua aktor dari unsur good governance. Para pejabat publik, unsur-unsur dalam masyarakat sipil dan dunia usaha sama-sama memiliki kepentingan terhadap perbaikan kinerja pelayanan publik. Ada tiga alasan penting yang melatarbelakangi bahwa pembaharuan pelayanan publik dapat mendorong praktik good governance di Indonesia. Pertama, perbaikan kinerja pelayanan publik dinilai penting oleh stakeholders, yaitu pemerintah, warga, dan sektor usaha. Kedua. Pelayanan publik adalah ranah dari ketiga unsur governance melakukan interaksi yang sangat intensif.

Ketiga, nilai-nilai yang selama ini mencirikan praktik good governance diterjemahkan secara lebih mudah dan nyata melalui pelayanan publik.

Fenomena pelayanan publik oleh birokrasi pemerintah sarat dengan permasalahan, misalnya prosedur pelayanan yang bertele- tele, ketidakpastian waktu dan harga yang menyebabkan pelayanan menjadi sulit dijangkau secara wajar oleh masyarakat. Hal ini menyebabkan terjadi ketidakpercayaan kepada pemberi pelayanan dalam hal ini birokrasi sehingga masyarakat mencari jalan alternatif untuk mendapatkan pelayanan melalui cara tertentu yaitu dengan memberikan biaya tambahan.

Di samping permasalahan di atas, juga tentang cara pelayanan yang diterima oleh masyarakat yang sering dilecehkan 
martabatnya sebagai warga negara.

Masyarakat ditempatkan sebagai klien yang membutuhkan bantuan pejabat birokrasi, sehingga harus tunduk pada ketentuan birokrasi dan kemauan dari para pejabatnya. Hal ini terjadi karena budaya yang berkembang dalam birokrasi selama ini bukan budaya pelayanan, tetapi lebih mengarah kepada budaya kekuasaan.(Amalia, 2018)

Kualitas pada dasarnya terkait dengan pelayanan yang terbaik, yaitu suatu sikap atau cara karyawan dalam melayani pelanggan atau masyarakat secara memuaskan. Menu-rut Triguno (1997 : 78) pelayanan / penyampaian terbaik, yaitu "melayani setiap saat, secara cepat dan memuaskan, berlaku sopan, ramah dan menolong, serta profesional dan mampu".

Menurut Wycof (dalam Tjiptono, 1996 : 59) "kualitas jasa/layanan adalah tingkat keunggulan yang diharapkan dan pengendalian atas tingkat keunggulan tersebut untuk memenuhi keinginan pelanggan". Ini berarti bila jasa/layan- an yang diterima (perceived service) sesuai dengan yang diharapkan maka kualitas layanan/jasa dipersepsikan baik dan memuaskan. Jika jasa yang diterima melampaui harapan pelanggan maka kualitas jasa/layanan dipersepsikan sebagai kualitas yang ideal, sebaliknya bila jasa/layanan yang di- terima lebih rendah dari pada yang diharapkan, maka kualitas jasa/layanan akan dipersepsikan buruk.

Dengan demikian baik tidaknya kualitas jasa/layanan tergantung pada kemampuan penyediaan jasa/layanan dalam memenuhi harapan pelanggan secara konsisten dan berakhir pada persepsi pelangan. (Nurdin, 2019).

Kabupaten Sidenreng Rappang sebagai daerah otonom berdasarkan pengamatan awal memperlihatkan kinerja yang masih jauh dari maksimal apabila dikaitkan dengan kontribusi. (Mustanir \& Jusman, 2016)

\section{HASIL DAN PEMBAHASAN}

Dalam hal pelaksanaan mahasiswa yang magang di unit bank untuk keperluan MBKM (Merdeka Belajar Kampus Merdeka), yang berpartisipasi dalam hal meningkatkan pelayanan di bank unit otting karena setiap pelanggan atau nasabah selalu ingin mendapatkan pelayanan yang cepat dan tepat. Mungkin hanya terdapat $1 \mathrm{CS}$ (customer servis) Dan 1 teller jadi hal yang diminta pelanggan tidak tercapai sehingga mereka kurang puas dengan pelayanan yang ada di bank unit otting. Berbagai hal yang biasanya mahasiswa kerjakan di bank seperti

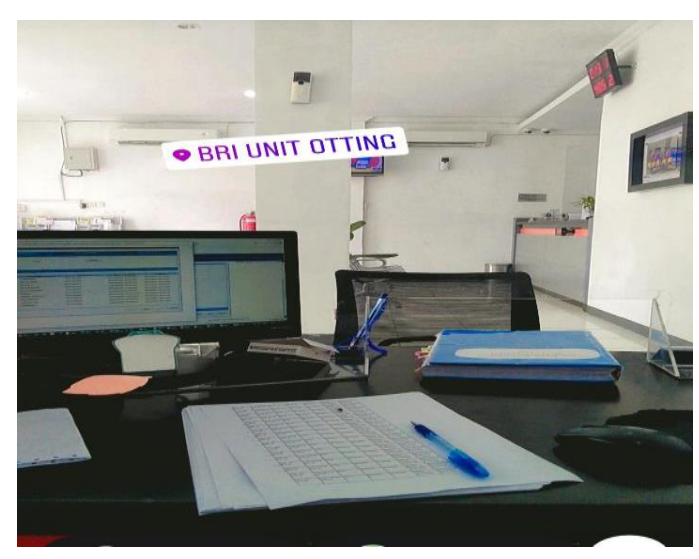

Gambar 1. Pengisian chip maintence 




Gambar 2. Pergantian kepala unit BRI Otting

Di setiap Unit Bank ada biasanya yang dinamakan MUTASI atau Pemindahan pegawai dari satu jabatan ke jabatan lain.

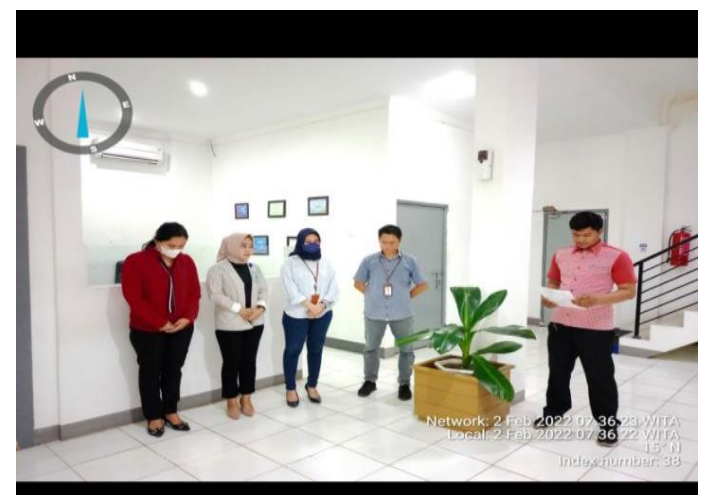

Gambar 3. Pembacaan Doa setiap pagi

Apel atau pembacaan doa setiap hari sebelum melaksanakan pekerjaan di Bank Unit Otting.

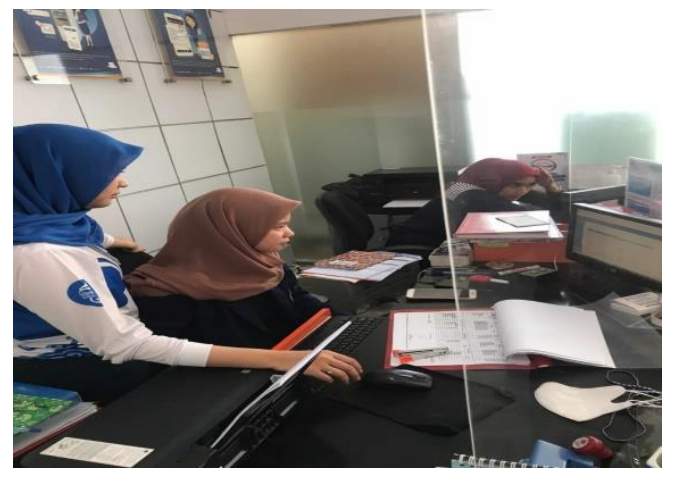

Gambar 4. Pengisian Biodata penerima

Tabungan Simpedes untuk pelajar.

Penerima Tabungan Simpedes untuk pelajar sekolah dasar yang berada di wilayah otting termasuk yang sudah di daftar oleh sekolahnya masing-masing.

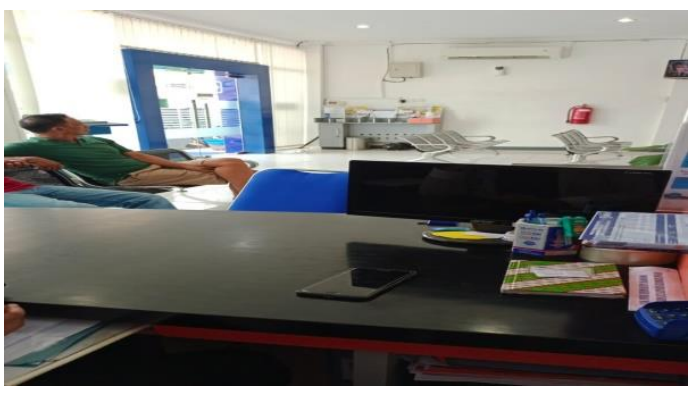

Gambar 5. Melayani pembuatan buku rekening, atm dan pencairan kredit.

\section{SIMPULAN DAN SARAN}

Penyelenggaraan publik tidak bisa dilepaskan dari standar pelayanannya. Standar inilah yang kemudian menjadi tolok ukur pelayanan yang berfungsi sebagai pedoman penyelenggaraan pelayanan publik.

Pedoman ini berfungsi sebagai acuan bagi pelaksana pelayanan publik dan para pengguna pelayanan dalam memenuhi dan memperoleh hak serta kebutuhan dasarnya.

Standar pelayanan juga diperlukan dalam upaya menilai efektivitas pelayanan yang diberikan oleh pegawai bank unit otting serta mengukur kepuasan masyarakat saat mengakses pelayanan. Penilaian itulah yang kemudian bisa dijadikan landasan untuk memperbaiki kualitas pelayanan agar 
penyelenggaraannya semakin berkualitas, mudah, cepat, terjangkau dan terukur.

Sekurang-kurangnya Standar pelayanan tersebut wajib disusun, ditetapkan dan diterapkan sehingga diketahui oleh masyarakat luas yang mengakses pelayanan. (Rohman \& Larasati, 2020)

\section{DAFTAR RUJUKAN}

Amalia, S. (2018). Reformasi Birokrasi 4.0 : Strategi Menghadapi Revolusi Industri 4.0. Jurnal Wacana Kinerja: Kajian Praktis-Akademis Kinerja Dan Administrasi Pelayanan Publik, 21(2), $1-18$.

https://doi.org/10.31845/jwk.v21i2.133

Andi Uceng, A. A. (2019). Analisis Tingkat Partisipasi Masyarakat Terhadap Pembangunan Sumber Daya Manusia Di Desa Cemba Kecamatan Enrekang Kabupaten Enrekang. MJurnal Moderat, 5(2), 1-17.

Fitrah, N., Mustanir, A., Akbari, M. S., Ramdana, R., Nisa, N. A., Qalbi, N., \& Febriani, A. F. (2021). Pemberdayaan Masyarakat Melalui Pemetaan Swadaya Dengan Pemanfaatan Teknologi Informasi Dalam Tata Kelola Potensi Desa. SELAPARANG : Jurnal Pengabdian Masyarakat Berkemajuan, 5(1), 337-344. https://play.google.com/store/books/det ails/Irwan_S_I_P_M_A_P_Pendekatan _Partisipatif_Implemen?id=XRJOEAA AQBAJ\&hl=in\&gl=US

Kurdi, M. (2020). Menggagas Pelayanan Prima di Masa Pandemic Covid 19. Jurnal Lingkar Widyaiswara, 04, 4-9. https://docplayer.info/198685155Menggagas-pelayanan-prima-di-masa- pandemic-covid-19.html

Latif, A., Rusdi, M., Mustanir, A., \& Sutrisno, M. (2019). Partisipasi Masyarakat Dalam Pembangunan Infrastruktur Di Desa Timoreng Panua Kecamatan Panca Rijang Kabupaten Sidenreng Rappang Dosen Ilmu Pemerintahan Stisip Muhammadiyah Rappang Dosen Ilmu Administrasi Negara Stisip Muhammadiyah Rappang 5). Jurnal MODERAT, 5(1), 1-15. https://jurnal.unigal.ac.id/index.php/mo derat/article/view/1898

Mustanir, A., \& Abadi, P. (2017). Partisipasi Masyarakat Dalam Musyawarah Rencana Pembangunan Di Kelurahan Kanyuara Kecamatan Watang Sidenreng Kabupaten Sidenreng Rappang. Jurnal Politik Profetik, 5(2), 247-261. http://journal.uinalauddin.ac.id/index.php/jpp/article/vie wFile/4347/3986\%0Ahttp://journal.uinalauddin.ac.id/index.php/jpp/issue/view /636

Mustanir, A., \& Darmiah, D. (2016). Implementasi Kebijakan Dana Desa Dan Partisipasi Masyarakat Dalam Pembangunan Di Desa Teteaji Kecamatan Tellu Limpoe Kabupaten Sidenreng Rappang. Jurnal Politik Profetik, 4(2), 225-238.

http://journal.uinalauddin.ac.id/index.php/jpp/article/vie w/2749\%0Ahttp://journal.uinalauddin.ac.id/index.php/jpp/issue/view 1457

Mustanir, A., Dema, H., Syarifuddin, H., Meity, K., \& Wulandari, S. (2018). Pengaruh Motivasi dan Partisipasi Masyarakat terhadap Pembangunan di Kelurahan Lalebata Kecamatan Panca Rijang Kabupaten Sidenreng Rappang. Jurnal Ilmiah Clean Government (JCG), 2(1), 27-39. 
http://lonsuit.unismuhluwuk.ac.id/index .php/clean/article/view/212

Mustanir, A., \& Jaya, I. (2016). Pengaruh

Kepemimpinan Dan Budaya Politik

Terhadap Perilaku Pemilih Towani

Tolotang Di Kecamatan Maritengngae

Kabupaten Sidenreng Rappang. Jurnal

Politik Profetik, 4(1), 84-97.

http://journal.uin-

alauddin.ac.id/index.php/jpp/article/vie w/2741\#\%0Ahttp://journal.uin-

alauddin.ac.id/index.php/jpp/issue/view 1430

Mustanir, A., \& Jusman. (2016).

Implementasi Kebijakan Dan

Efektivitas Pengelolaan Terhadap

Penerimaan Retribusi Di Pasar

Lancirang Kecamatan Pitu Riawa

Kabupaten Sidenreng Rappang. Jurnal

Ilmiah Akmen, 13(3), 542-558.

https://e-jurnal.stienobel-

indonesia.ac.id/index.php/akmen/article /view/69\%0Ahttps://e-jurnal.stienobelindonesia.ac.id/index.php/akmen/issue/ view/6

Nurdin, I. (2019). Kualitas Pelayanan Publik (Perilaku Aparatur Dan Komunikasi Birokrasi Dalam Pelayanan Publik). 20.

Rohman, A., \& Larasati, D. C. (2020). Standar Pelayanan Publik Di Era Transisi New Normal. Reformasi, 10(2), 151-163.

https://doi.org/10.33366/rfr.v10i2.1952 